\title{
Modeling of a Cogeneration System with a Micro Gas Turbine Operating at Partial Load Conditions
}

\author{
José C. Dutra"1, Maria A. Gonzalez-Carmona', Andrés F. Lazaro-Alvarado ${ }^{3}$, \\ Alberto Coronas ${ }^{4}$ \\ ${ }^{1}$ Department of Mechanical Engineering, Federal University of Pernambuco, Av. Prof. Moraes Rego, \\ 1235, CEP 50670-901 Recife, PE, Brazil \\ e-mail: charamba@gmail.com \\ ${ }^{2}$ Department of Mechanical Engineering, Federal University of Pernambuco, Av. Prof. Moraes Rego, \\ 1235, CEP 50670-901 Recife, PE, Brazil \\ e-mail: angelica.gonzalez@ufpe.br
}

${ }^{3}$ CREVER, Department of Mechanical Engineering, Rovira i Virgili University, Av. Països Catalans 26, 43007 Tarragona, Spain e-mail: andresfelipe.lazaro@urv.cat

${ }^{4}$ CREVER, Department of Mechanical Engineering, Rovira i Virgili University, Av. Països Catalans 26, 43007 Tarragona, Spain

e-mail: alberto.coronas@urv.cat

Cite as: Dutra, J. C., Gonzalez-Carmona, M. A., Lazaro-Alvarado, A. F., Coronas, A., Modeling of a Cogeneration System with a Micro Gas Turbine Operating at Partial Load Conditions, J. sustain. dev. energy water environ. syst., 5(2), pp 139-150, 2017, DOI: http://dx.doi.org/10.13044/j.sdewes.d5.0138

\begin{abstract}
The integration of absorption chillers in micro-cogeneration systems based on micro-gas turbines can be useful as an appropriate strategy to increase the total system energy efficiency. Since it is an area intensive in technology, it is necessary to develop and use models of simulation, which can predict the behavior of the whole system and of each component individually, at different operating conditions. This work is part of a research project in high efficiency cogeneration systems, whose purpose at this stage is to model a micro-cogeneration system, which is composed of a micro gas turbine, Capstone C30, a compact cross flow finned tube heat exchanger and an absorption chiller. The entire model is composed of specifically interconnected models, developed and validated for each component. The simulation of the microturbine used a thermodynamic analytic model, which contains a procedure used to obtain the micro turbine characteristic performance curves, which is closed with the thermodynamic Brayton cycle model. In the cogeneration system discussed in this paper, the compact heat exchanger was used to heat thermal oil, which drives an absorption chiller. It was designed, characterized and installed in a cogeneration system installed at the Centre d'Innovació Tecnològica en Revalorització Energètica i Refrigeració, Universtat Rovira i Virgili. Its design led to the heat exchanger model, which was coupled with the micro turbine model. Presented in this work is a comparison between the data from the model and the experiments, demonstrating good agreement between both results.
\end{abstract}

\section{KEYWORDS}

Cogeneration system, Micro gas turbine, Mathematical modeling, Absorption chiller, Partial load.

\footnotetext{
* Corresponding author
} 


\section{INTRODUCTION}

The worldwide energy demands for the commercial and industrial buildings are increasing exponentially. That implies that the energy supply must increase too. However, to meet the energy demands, the cost to construct new, for example, hydroelectric or thermoelectric plants are increasing faster than the rate of inflation. One has also to consider the increased cost of transmission over long distances from the power plants. To mitigate the increasing costs of new power plants and of transmission, the alternative solution is to generate power by means of distributed power generation sources.

The generation of energy by fossil fuels normally does not make use of energy content in the exhaust gases. This wastage of energy needs to be recuperated by the techniques of cogeneration/micro-cogeneration. The cogeneration, in general, leads to increased profitability of power system, and is being given extra importance in view of the energy efficiency of the power system.

Especially in the case of micro-cogeneration, it becomes necessary to take into account all the variations such as daily and seasonal variations of the power demand to be able to predict the overall behavior of the micro-cogeneration system. For example, in the case of micro gas turbines coupled with the distributed energy system, it has been observed that these are thermally efficient (because of low thermal inertia) as it permits to achieve full load in a short interval of time.

Some authors have reported on how a city can supply heating to each end-user by taking advantage of the wasted thermal energy of the cogeneration systems, and on regulations. Li et al. [1] have put forward a computational tool for the design, configuration and optimization of a district heating network which uses a Genetic Algorithm. Garmston [2] presented an analysis about a policy on energy regulations for buildings in England and Wales. Other authors have also made a critical analysis on sustainable buildings and urban development. Tardieu [3] conducted an analysis of the regulations for buildings energy quality in urban development projects developed in Paris. Moreover, Czarnowska [4] has studied the application of some numerical methods to the thermo-ecological life cycle cost of heat exchanger components. Furthermore, Gomez [5] has investigated the importance of technology for social inclusion. The case study he presented, analyzed the importance of access to electricity in the Brazilian Amazon. In the same way, Gavira [6] has investigated development financing in the renewable energy industry in Brazil.

In addition, there are also publications on the analytic model for cogeneration systems which include how these were validated and case studies, such as Di Palma [7], who presented a calculation model for the trigeneration plants projects, which can evaluate all the incentivizing mechanisms. On the other hand, Chacartegui [8] has published a study about the potential of organic rankine cycle systems to be used as retrofit cogeneration plants in wastewater treatment stations.

Hence, there is clearly a need to develop computational tools to simulate cogeneration systems. Mohammed [9], has presented an approach to studying some strategies for reducing energy consumption and has applied it in a student cafeteria. Mikulandrić [10] has presented a model to calculate and analyze the performance of a hybrid district heating system.

A gas turbine is one of the most important prime movers in a cogeneration system, and in this paper special emphasis is given to modeling this, drawing on some of the studies of authors who have already published articles on modeling a gas turbine. This will certainly help estimate the behavior in different operating modes. [11] provides an overview of current and future sustainable turbine technologies. Okelah [12], using a manufacturer's data map, presents thermodynamic and mathematical analysis to calculate 
the effects of the design parameters on the performance of the turbine's components. $\mathrm{Al}$ Hamdan [13] modeled and simulated a single-axle gas turbine engine for power generation. On the other hand, Mohanty [14] investigated the behavior of the performance of a gas turbine by cooling the inlet air using an absorption chiller.

Aklilu et al. [15] developed a model to simulate the part-load operation of a single shaft gas compressor with variable geometry, while Zhang and Cai [16] presented an analytic procedure to generate the characteristic curves of a micro-turbine. Malinowski [17] presented an analytic model to calculate the performance of a set of gas turbines. It consists of a thermodynamic model, coupled with the above-mentioned procedure proposed by Zang, to predict the behavior of a microturbine. The importance of this kind of computational tool is because turbine manufacturers, for commercial reasons, do not publish the characteristic curves of their turbines and compressors.

Thus, it is by developing numerical models for the components and for the entire system that it becomes possible for manufacturers and research groups to have their own design and simulation tool. This is why the aim of this work is to develop a model that is able to predict micro-cogeneration behavior. Alvarado et al. [18] presented a comparison between the data generated by the Malinowski mode [17] and the experimental data obtained at the CREVER laboratory at URV for a micro turbine (Capstone C30) operating at varying loads and climatic conditions were presented by Amaris [19] who obtained experimental data from the exhaust gas of one microturbine, so as to activate an absorption chiller of ammonia. Moya [20] used micro-trigeneration advanced systems with gas microturbines and absorption chillers for air dissipation. The model can also estimate behavior at part or full load, with ISO or no ISO conditions, with a high degree of accuracy.

In the present work, the model of a micro turbine was coupled to one of a compact heat exchanger, and it was used to simulate micro cogeneration system. The experimental data are compared to the model data.

\section{MODELLING A COGENERATION SYSTEM}

The model presented in this article, is of one part of the cogeneration system mentioned previously. It consists of the analytical model of a micro turbine, interconnected with the model of a compact heat exchanger, to recover the heat from the exhaust gases and transfer it to the thermal oil, with the final goal being the activation of the absorption chiller. In the following sections, these models are described.

\section{Micro turbine thermodynamic analytical model}

The knowledge of the pressure ratios and efficiency parameters is essential for the simulation of a real turbine. In general, these are obtained through the characteristic curves that are the property of the manufacturer, and are not easy to get. Because of this, Zang [20] proposed a semi-empirical method to calculate such parameters of the turbine main components.

Characteristics curve procedure. This procedure uses dimensionless semi-empirical equations to calculate the pressure ratios and efficiencies of the compressor and turbine parameters, as a function of the relative turbine shaft rotational speed and the relative mass flow, as presented in Alvarado [18]. It is a useful tool because part load data for the micro turbine operating at different ambient conditions, for example, was not included in the technical data provided by the manufacture.

To give an idea of how it is done, two of these dimensionless semi-empirical equations, i.e., eq. $(19,20)$ in $[18]$, used to predict the pressure ratio and efficiency of the 
compressor are presented. Analogue equations are used to calculate also the pressure ratio and efficiency of the micro turbine:

$$
\begin{gathered}
\tilde{\sigma}=C_{1} \cdot \widetilde{m}_{\mathrm{c}}^{2}+C_{2} \cdot \widetilde{m}_{\mathrm{c}}+C_{3} \\
\tilde{\eta}=\left[1-C_{4}\left(1-\tilde{n}_{\mathrm{c}}\right)^{2}\right]\left(\frac{\tilde{n}_{\mathrm{c}}}{\tilde{m}_{\mathrm{c}}}\right)\left[2-\left(\frac{\tilde{n}_{\mathrm{c}}}{\widetilde{m}_{\mathrm{c}}}\right)\right]
\end{gathered}
$$

where $C_{1}, C_{2}, C_{3}, C_{4}$ are parameters obtained by correlations with experimental data.

These dimensionless equations of the compressor and turbine are functions of the relative rotational speed and the relative mass flow (as described in [19, 20]).

The compatibility of the rotational speed, the dimensionless flows between the compressor and the turbine, and the modified Flügel formula constitute a system of which the solution generates the characteristic curves.

Thermodynamic approach. The model to simulate the micro turbine was developed taking into account that the turbine can be modelled under the assumption that it works like a Brayton regenerative cycle. Malinowski [17] coupled the above-mentioned procedure to calculate the characteristic curves coordinates, with the energy, entropy and mass balance equations, to simulate a micro turbine. Incidentally, it was done under some basic assumptions as presented in Malinowski [20], including the assumption that the UA for exhaust gas heat recovery was considered constant.

The modelling development was done by applying an energy, an entropy, and a mass balance to each of the micro turbine components, i.e., the first and second laws of thermodynamics, and the continuity equation for each component. Thereby, the balances done with the first and second laws of thermodynamics and the continuity equation of each component lead to an equations system, whose solution predicts the micro turbine behavior at part load and nonstandard altitude and atmospheric conditions. Besides calculating performance parameters, it also calculates the values of the electrical power generated in fuel burner, the work of the compressor and of the turbine, the electricity generated, and the heat rejected in the exhausted gases.

Since the real expansion and compression processes deviate from the isentropic, it is necessary to introduce the isentropic efficiency equation to calculate the enthalpy at the non-isentropic states. The value of isentropic efficiency of the compressor and the turbine is calculated using the analytical procedure mentioned previously:

$$
\eta_{\mathrm{S}}=\frac{h_{2}-h_{1}}{h_{2 S}-h_{1}}
$$

Another important parameter in the simulation is the pressure drop calculation. In order to calculate this at the outlet of the turbine or compressor, it is necessary to have pressure relation value $\sigma_{j}$. This is calculated during the analytical procedure, and the parameter $k_{j}$, that represents the relative percentage of pressure drop. It is calculated as [17]:

$$
k_{j}=k_{j 0}\left(\frac{m}{m_{0}}\right)^{2}\left(\frac{p_{j 0}}{p_{j}}\right)^{2}\left(\frac{T_{j}}{T_{j 0}}\right)^{2}
$$

where subscript 0 indicates parameters for rated load.

So, the pressure drop is calculated as: 


$$
p_{i+1}=\left(1-k_{j}\right)
$$

where $i$ and $i+1$ are the initial and final points of the compression or expansion process.

The $k$ values used here for the standard conditions of the components of the micro turbine can be seen being used by Malinowski [17]. Moreover, the $k$ used to calculate the pressure outlet of the micro turbine takes into account the pressure drop due to the internal heat recovery.

This paper used the model presented by Malinowski [17] to predict the performance of a single shaft micro turbine Capstone C30 of the CREVER laboratory, and to compare the results with the experimental data obtained by the previously-mentioned equipment operating nonstandard conditions, at the bench teste of the CREVER Laboratory, as presented by Lazaro-Alvarado [18]. Since it showed good agreement with the experimental data, it was taken as a simulating tool to compose a whole cogeneration model in development, which is the objective of this work.

\section{Some results from microturbine model}

Because the model describes the behavior of the gas micro turbine at full load, or partial load, in standard and nonstandard conditions, it was chosen to present the capability, and the effect of inlet air temperature of the micro turbine on the turbine outlet temperature $\left(T_{4}\right)$, shown in Figure 1. This data was obtained considering the turbine operating with a fixed electrical power of $23 \mathrm{~kW}$ as presented in reference [18].

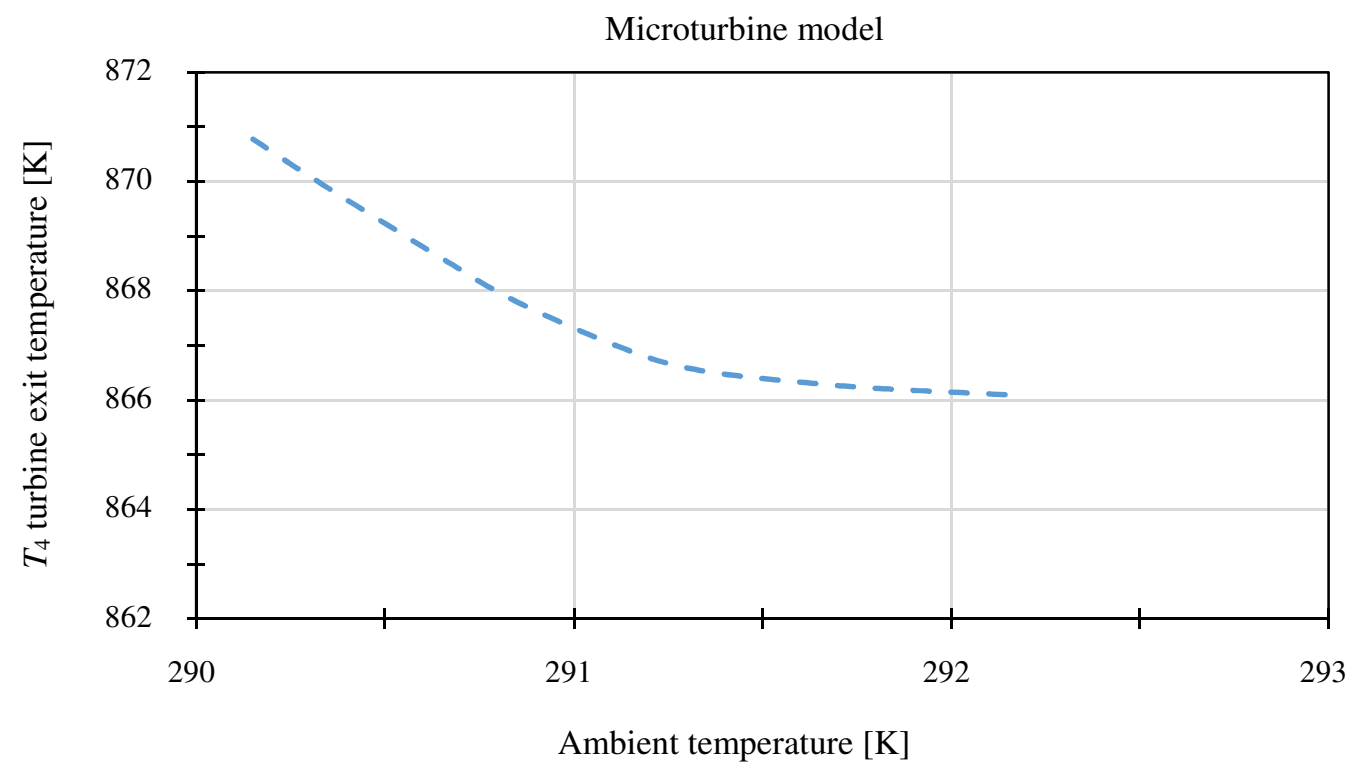

Figure 1. Effect of inlet air temperature to the outlet temperature $\left(T_{4}\right)$ of the exhausted gases of the micro turbine to a demanded load of $23 \mathrm{~kW}$

\section{Exhaust gas heat recovery}

The heat recovery was designed and built by a manufacturer of boilers, taking a thermal flow oil and constant micro turbine load of $23 \mathrm{~kW}$ as a base. Under these conditions, a cross-flow compact heat exchanger was designed and built.

The tube bundle has 120 finned SS316L stainless steel tubes, $616 \mathrm{~mm}$ long with 18 passes in the tubes bundle, which have transversal and longitudinal pitches of 38 and $33 \mathrm{~mm}$. The overall dimensions of the exchanger are of length $707 \mathrm{~mm}$ and $380 \mathrm{~mm}$ in width. In Figure 2, part of its body can be seen, which is composed of three tube bundles, connected in series. The figure shows also how the finned tubes are fixed to the tube sheet. 

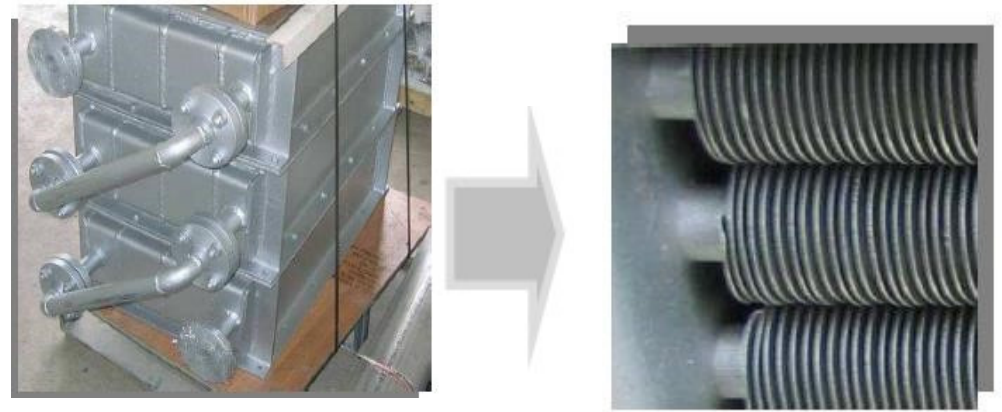

Figure 2. View of the shell of the heat exchanger and detail of the finned tube

Pressure drop. The $k$ used to calculate the pressure drop in the oil-gas heat recovery was obtained from the manufacturer as $k_{\mathrm{hx} 0}=0.16$.

It was observed that it is almost ten times the same parameters to the components of the turbine, and since it was done with the micro turbine, the $k$ values to the system operating at part load, have to be corrected using eq. (4).

\section{HEAT RECOVERY CHARACTERIZATION}

With the known geometric dimensions of the heat recovery, and the data obtained in the experiments, the load of $23 \mathrm{~kW}$, and the flow rate of thermal oil were chosen and a simulation was carried out, as displayed in Table 1. Table 2 shows the thermal physical data used in this simulation.

Table 1. Simulation done with Aspen HTFS

\begin{tabular}{cccccc}
\hline Fluids & $\begin{array}{c}\text { Heat transfer } \\
{[\mathrm{kW}]}\end{array}$ & $\begin{array}{c}U A \\
{[\mathrm{~W} / \mathrm{K}]}\end{array}$ & $\begin{array}{c}\text { LMTD } \\
{[\mathrm{K}]}\end{array}$ & $\begin{array}{c}Q_{\max } \\
{[\mathrm{kW}]}\end{array}$ & $\begin{array}{c}\text { Thermal efficiency } \\
\text { of the heat recovery } \\
\eta_{\mathrm{Hxr}}\end{array}$ \\
\hline $\begin{array}{c}\text { Thermal oil } \\
\text { Exhausted gases }\end{array}$ & $\begin{array}{c}17.95 \\
17.47\end{array}$ & 0.77 & 23.3 & 18.44 & 0.97 \\
\hline
\end{tabular}

Applying the heat exchanger geometric dimensions and the thermal physical parameters shown in Table 2, a simulation was carried out using the method of global coefficient, and the method of efficiency, the heat flows transferred between the two fluids, the LMTD and the $U A$ value, were calculated and are presented in Table 2 . These results show that the heat recovered is enough for operating the absorption chiller.

Table 2. Data used in teste and simulation ASE

\begin{tabular}{ccccc}
\hline Fluids & $\begin{array}{c}\text { Temperature } \\
\text { inlet }[\mathrm{K}]\end{array}$ & $\begin{array}{c}\text { Temperature } \\
\text { outlet }[\mathrm{K}]\end{array}$ & $\begin{array}{c}\text { Specific heat } \\
{[\mathrm{kJ} / \mathrm{kgK}]}\end{array}$ & $\begin{array}{c}\text { Flow } \\
{[\mathrm{kg} / \mathrm{s}]}\end{array}$ \\
\hline Thermal oil & 460.48 & 473.55 & 2.662 & 0.519 \\
Exhaust gases & 557.05 & 463.05 & 1.002 & 0.1869 \\
\hline
\end{tabular}

Heat exchanger simulation with Aspen HTFS 2006. The Aspen HTFS uses a more accurate mathematical model, based on a more rigorous approach, which contributed to a more reliable algorithm for simulating the heat exchanger behavior. Using this, convection coefficients, for both fluids, the global coefficient, and the LMTD were calculated, as shown in Table 3. 
Table 3. Some results from the simulation

\begin{tabular}{cccccc}
\hline Fluids & $\begin{array}{c}\text { Coefficient } \\
\text { of convection } \\
{\left[\mathrm{kW} / \mathrm{m}^{2} \mathrm{~K}\right]}\end{array}$ & $\begin{array}{c}U \\
{\left[\mathrm{~kW} / \mathrm{m}^{2} \mathrm{~K}\right]}\end{array}$ & $\begin{array}{c}\text { LMDT } \\
{[\mathrm{K}]}\end{array}$ & $\begin{array}{c}\text { Effective } \\
\text { area }\left[\mathrm{m}^{2}\right]\end{array}$ & $\begin{array}{c}\text { Thermal efficiency of } \\
\text { the heat recovery } \\
\eta_{\mathrm{Hxr}}\end{array}$ \\
\hline $\begin{array}{c}\text { Thermal oil } \\
\text { Exhausted gases }\end{array}$ & $\begin{array}{c}1,445.9 \\
272.7\end{array}$ & 226.7 & 20.65 & 3.9 & 0.97 \\
\hline
\end{tabular}

The utilization of Aspen software made several simulations possible. Some of them were done considering the thermal oil flow variation in a specific range. Other tests were carried out varying the inlet temperature and the flow of the exhaustion gases of the micro turbine.

\section{COGENERATION SYSTEM TESTS IN A BENCH TEST}

Several tests were done with this heat exchanger coupled with the cogeneration system installed at the test bench in the laboratory of the CREVER-URV. Some were done with the micro turbine operating at a constant load, the oil flow varying in a defined range. Some were done for a fixed thermal oil flow of $0.51 \mathrm{~kg} / \mathrm{s}$, and the turbine operating at different loads. In each test, the turbine load, the pressures, and the flows and temperatures of the oil and of the exhaust gases at the inlet and outlet of this heat recovery were measured. The following diagram shows the process flow of the experimental cogeneration system (as Figure 3).

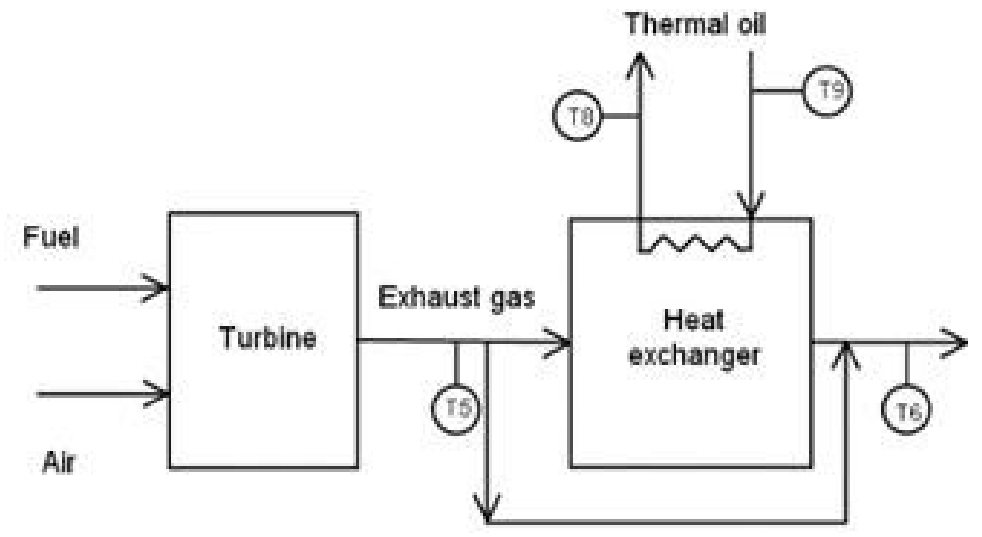

Figure 3. Diagram of the process of the experimental cogeneration system

The measured data was taken and registered every second by the data acquisition system installed at the test bench.

This data was subjected to statistical analysis to determine the most representative value for both dependent and independent variables. A confidence interval where the average values are contained was calculated. In this article, some results of the tests that were made on the bank of tests are presented and described in Moya [2].

The experimental data obtained in the tests described in Moya [2] was compared to the numerical data to verify the validity of the Aspen model used with this kind of heat exchanger. In addition, the comparison between the two kinds of data shows good agreement between them, as presented by Amaris [1]. It seems that with the heat exchanger characterization carried out with these obtained parameters, a simple and accurate model capable of predicting the heat recovery behavior in operation can be built.

The data used in Figure 4 was obtained by the micro turbine operating at partial loads varying in an interval of $6 \mathrm{~kW}$ to $23 \mathrm{~kW}$, at an average ambient temperature of $292 \mathrm{~K}$. 


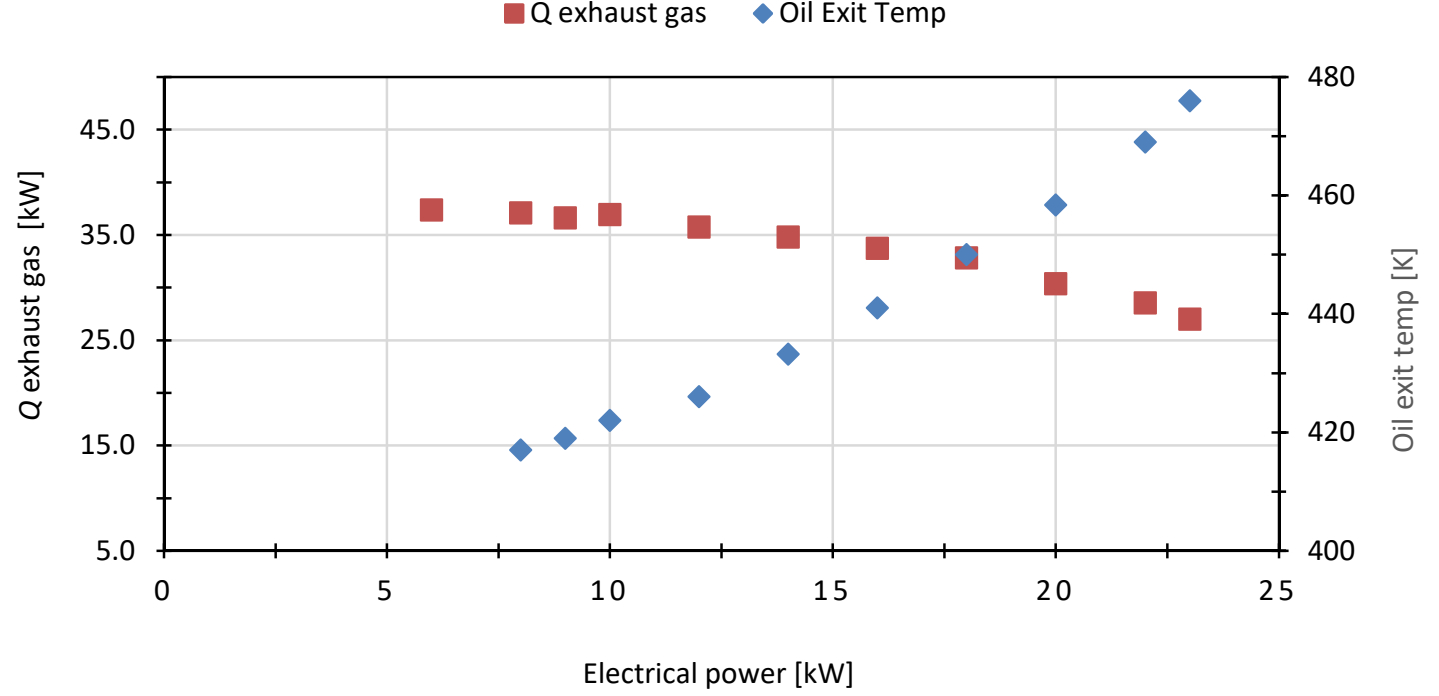

Figure 4. Variation of temperature of the oil at the outlet and the heat recovered from the exhaust gases of the heat exchanger at part load operation

\section{HEAT EXCHANGER MODELLING}

Figure 5 shows that the numerical and experimental data follow the same pattern, and that the model can predict how the oil temperature varies as the micro turbine part load varies. In the experiments, the load was changed from $6 \mathrm{~kW}$ to $23 \mathrm{~kW}$, and the inlet air at an average ambient temperature of $292 \mathrm{~K}$. It can be seen that the results fit well with the experimental measurements, and that temperatures model results have a maximum deviation of $3 \mathrm{~K}$.

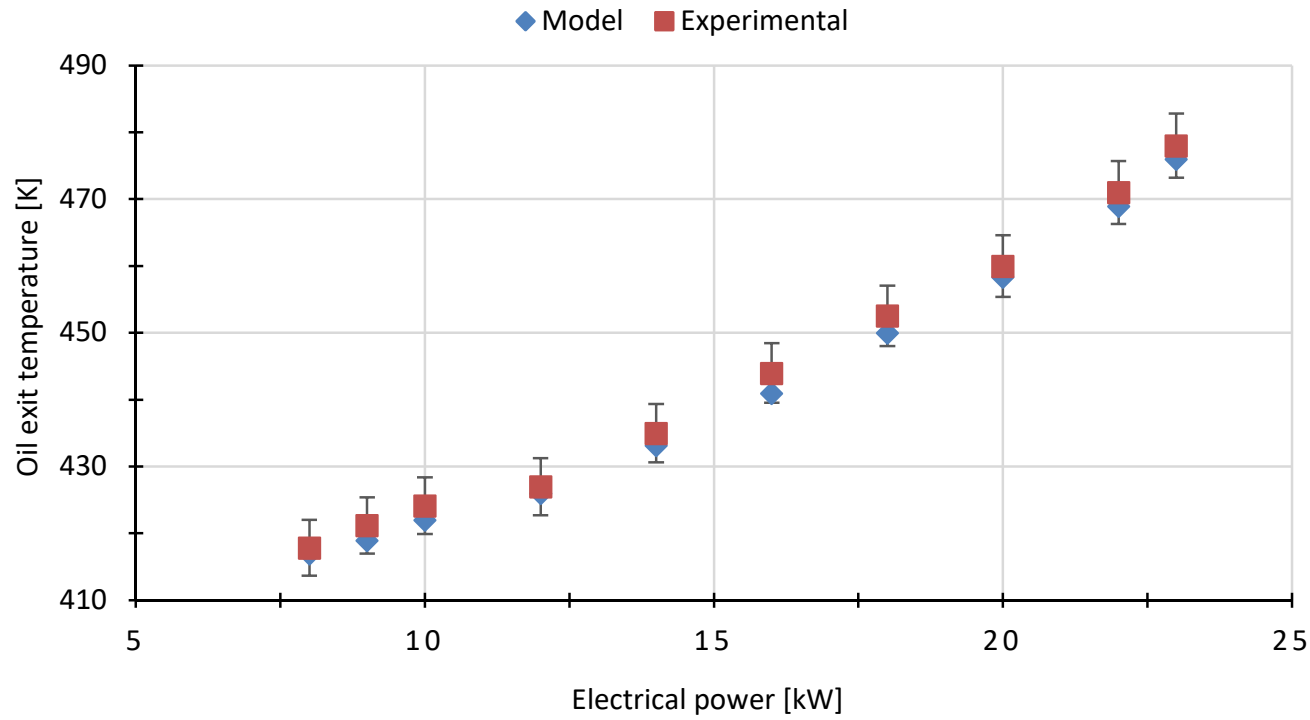

Figure 5. Comparison between the numerical and experimental data of thermal oil temperature at the outlet of the heat exchanger as the micro turbine part load varies

In Figure 6, good agreement between numerical and experimental data is demonstrated once again. The deviation between them for the heat output of the exhaust gas is shown, obtained to the micro turbine operating during the variation in the part load at the same range as previously-mentioned. In the calculation of the exhaust gas, a maximum deviation between experimental and numerical values is presented, of $1.9 \%$ and an average of $0.9 \%$. 
Experiment Model

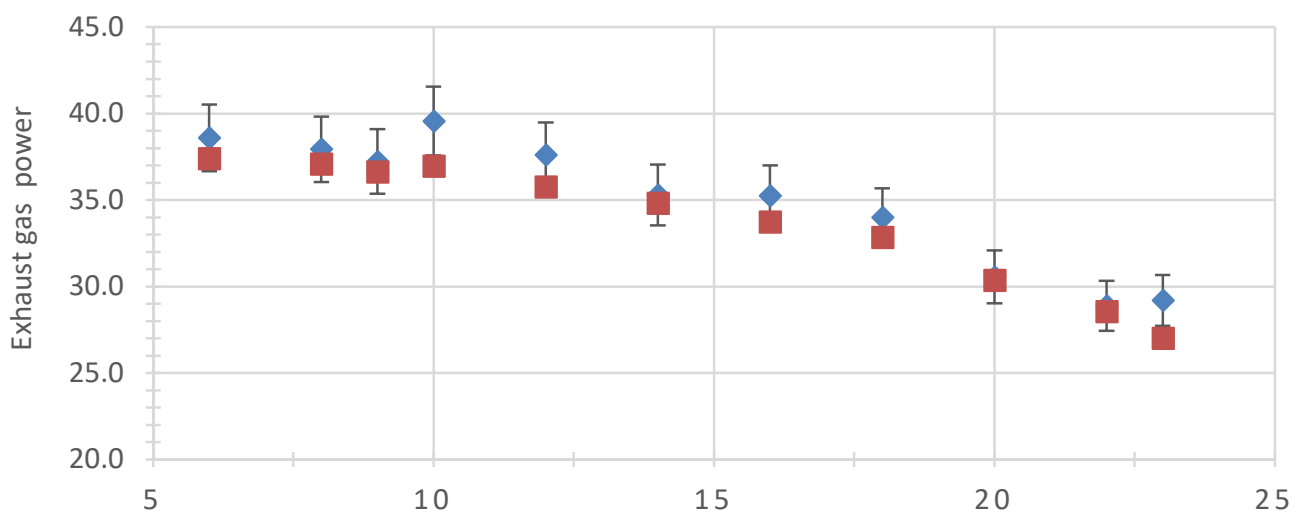

Electrical power $[\mathrm{kW}]$

Figure 6. Comparison of the model and the experimental data between the thermal power and electrical power

\section{IMPROVEMENT IN THE MODEL}

Although the earlier results show good agreement between experimental and numerical data, in spite of using a constant $U$, it is known that the overall coefficient is not constant and that it varies with the flow, and temperature.

Using the experimental data, the values of the global heat transfer coefficient at three values of thermal oil flow rates were calculated, and a correlation which was introduced in the model changer was adjusted. Figure 7 shows that $U$ varies linearly with the flow. But, the main resistance to the heat transfer between the two fluids is the exhaust gas resistance. With more experimental data and applying the ASPEN to calculate the global coefficients, to predict $U$ as a function of the flow and temperature variation, to introduce in the model.

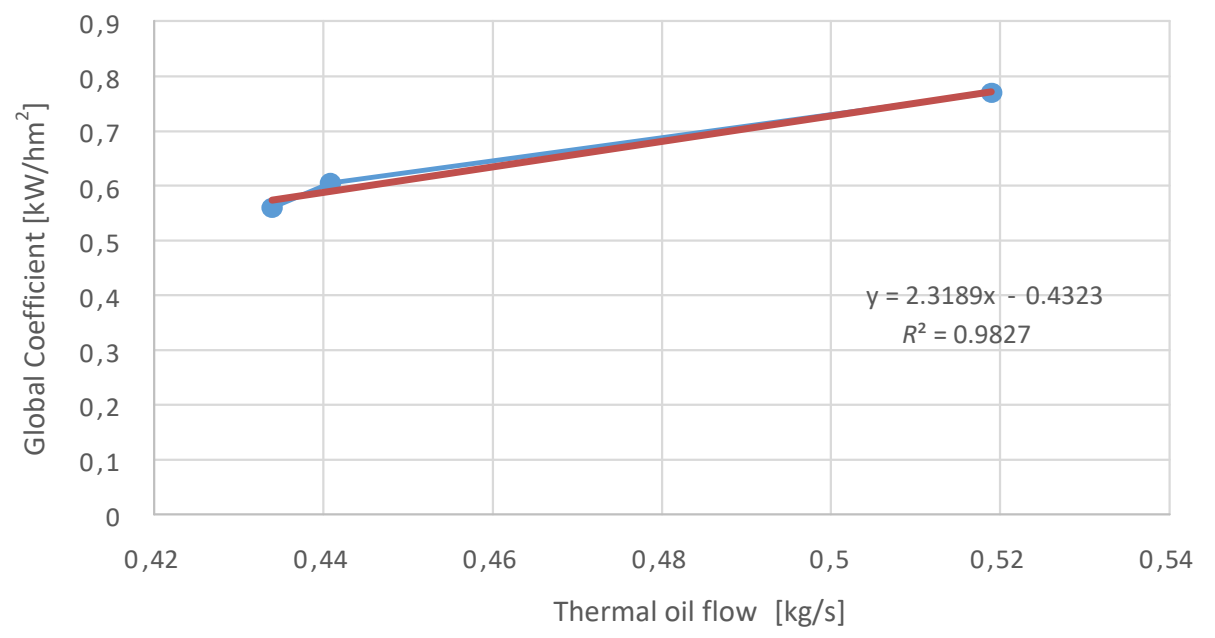

Figure 7. Effect on the Global Coefficient with thermal oil flow variation

\section{CONCLUSIONS}

The numerical data generated by the model, including the turbine simulations Alvarado [9], could predict quite well the behavior of the cogeneration system under the influence of inlet air temperature and the power demanded by the load in the turbine. 
It was verified that the maximum deviation in the temperatures of the thermal oil was of 3 degrees, while the rotational frequency does not deviate more than $0.15 \%$ compared to the experimental values, and the maximum deviation in temperatures of exhaust gases the micro turbine output of $1.9 \%$ and that these values are below the experimental.

Therefore, this whole model is able to predict the main parameters at any point in steady state operation. In addition, it makes it possible to analyze and make inferences about the behavior of a cogeneration system, at part load and at nonstandard conditions. Furthermore, it can calculate the electrical power generated, the heat of the exhaust gases of the micro turbine, temperatures of the micro turbine components, and outlet temperatures for the gases and thermal oil. The heat contained in the exhausted gases can be recovered by one waste heat recovery unit, which generates hot water that can be used to drive an absorption chiller. This heating process was modelled, and can predict the thermal oil and water temperatures at the heat exchanger outlets. So, the cogeneration model will be concluded by the addition of an analogous model to simulate the absorption chiller.

\section{ACKNOWLEDGEMENT}

The authors gratefully acknowledge the support of the Spanish Ministry of Economy and Competitiveness (DPI2012-38841-C02-01), CAPES (PVE 88887.062353/2014-00) CNPq (Bolsa PDE - CiênciassemFronteiras).

\section{NOMENCLATURE}

$\begin{array}{llc}h & \text { specific enthalpy } & {[\mathrm{kJ} / \mathrm{kg}]} \\ k & \text { relative pressure loss } & {[-]} \\ m & \text { mass flow rate through the compressor and turbine } & {[\mathrm{kg} / \mathrm{s}]} \\ n & \text { rotational speed } & {[\mathrm{rps}]} \\ p & \text { pressure } & {[\mathrm{kPa}]} \\ Q & \text { heat rate } & {[\mathrm{W}]} \\ R & \text { gas constant } & {[\mathrm{kJ} /(\mathrm{kgK})]} \\ s & \text { specific entropy } & {[\mathrm{kJ} / \mathrm{kgK}]} \\ T & \text { temperature } & {[\mathrm{K}]}\end{array}$

\section{Greek symbols}

$\begin{array}{ll}\eta_{\mathrm{Hxr}} & \text { heat exchanger recovery efficiency } \\ \eta & \text { efficiency }\end{array}$

\section{Subscripts and superscripts}

$\begin{array}{ll}\mathrm{c} & \text { compressor } \\ \mathrm{H}_{\mathrm{x}} & \text { heat exchanger } \\ \mathrm{r} & \text { heat recovery } \\ \mathrm{s} & \text { isentropic } \\ 0 & \text { design value } \\ \sim & \text { divided by design value }\end{array}$

\section{REFERENCES}

1. Li, H. and Svendsen, S., District Heating Network Design and Configuration Optimization with Genetic Algorithm, J. Sustain. Dev. Energy, Water and Environ. Syst., Vol. 1, No. 4, pp 291-303, 2013, http://dx.doi.org/10.13044/j.sdewes.2013.01.0022

2. Garmston, H. and Pan, W., Non-Compliance with Building Energy Regulations: The Profile, Issues, and Implications on Practice and Policy in England and Wales, 
J. Sustain. Dev. Energy, Water and Environ. Syst., Vol. 1, No. 4, pp 340-351, 2013, http://dx.doi.org/10.13044/j.sdewes.2013.01.0026

3. Tardieu, C., Colombert, M., Diab, Y. and Blanpain, O., Analysis of the Prescriptions for Energy Quality Buildings in Three Parisian Urban Development Projects, J. Sustain. Dev. Energy, Water and Environ. Syst., Vol. 3, No. 2, pp 118-130, 2015, http://dx.doi.org/10.13044/j.sdewes.2015.03.0009

4. Czarnowska, L., Litwin, W. and Stanek, W., Selection of Numerical Methods and their Application to the Thermo-Ecological Life Cycle Cost of Heat Exchanger Components, J. Sustain. Dev. Energy, Water and Environ. Syst., Vol. 3, No. 2, pp 131-139, 2015, http://dx.doi.org/10.13044/j.sdewes.2015.03.0010

5. Gomez, F. M., Sanches-Pereira, A. and Silveira, S., Technology for Social Inclusion: The Case of Electricity Access in the Brazilian Amazon, J. Sustain. Dev. Energy, Water and Environ. Syst., Vol. 1, No. 3, pp 237-259, 2013, http://dx.doi.org/10.13044/j.sdewes.2013.01.0018

6. Gavira, M. O., Research and Development Financing in the Renewable Energy Industry in Brazil, J. Sustain. Dev. Energy, Water and Environ. Syst., Vol. 2, No. 3, pp 208-218, 2014, http://dx.doi.org/10.13044/j.sdewes.2014.02.0017

7. Di Palma, D., Lucentini, M. and Rottenberg, F., Trigeneration Plants in Italian Large Retail Sector: a Calculation Model for the TPF Projects with Evaluation of all the Incentivizing Mechanisms, J. Sustain. Dev. Energy, Water and Environ. Syst., Vol. 1, No. 4, pp 375-389, 2013, http://dx.doi.org/10.13044/j.sdewes.2013.01.0028

8. Chacartegui, R., Muñoz de Escalona, J., Becerra, J. A., Fernández, A. and Sánchez, D., Potential of ORC Systems to Retrofit CHP Plants in Wastewater Treatment Stations, J. Sustain. Dev. Energy, Water and Environ. Syst., Vol. 1, No. 4, pp 352-374, 2013, http://dx.doi.org/10.13044/j.sdewes.2013.01.0027

9. Mohammed, M. A. and Budaiwi, I. M., Strategies for Reducing Energy Consumption in a Student Cafeteria in a Hot-Humid Climate: a Case Study, J. Sustain. Dev. Energy, Water and Environ. Syst., Vol. 1, No. 1, pp 14-26, 2013, http://dx.doi.org/10.13044/j.sdewes.2013.01.0002

10. Mikulandrić, R., Krajačić, G., Duić, N., Khavin, G., Lund, H., Vad Mathiesen, B. and Østergaard, P., Performance Analysis of a Hybrid District Heating System: a Case Study of a Small Town in Croatia, J. Sustain. Dev. Energy, Water and Environ. Syst., Vol. 3, No. 3, pp 282-302, 2015, http://dx.doi.org/10.13044/j.sdewes.2015.03.0022

11. Poullikkas, A., An Overview of Current and Future Sustainable Gas Turbine Technologies, Journal of Renewable and Sustainable Energy Reviews, Vol. 9, No. 5, pp 409-443, 2005, http://dx.doi.org/10.1016/j.rser.2004.05.009

12. Sayed Okelah, M. R., Optimization of the Design Parameters of a Co-turbo Shaft Gas Turbine Engine as a Heavy Equipment Power Plant, PhD Thesis, Carleton University, Ontario, 1980.

13. Qusai Al-Hamadan, Z. and Munzer Ebaid, S. Y., Modelling and Simulation of a Gas Turbine Engine for Power Generation, ASME Journal of Engineering for Gas Turbines and Power, Vol. 128, pp 302-310, 2006, http://dx.doi.org/10.1115/1.2061287

14. Mohanty, B. and Paloso Jr. J., Enhancing Gas Turbine Performance by Intake Air Cooling using an Absorption Chiller, Heat Recovery Syst. and CHP, Vol. 15, No. 1, pp 41-45, 1995, http://dx.doi.org/10.1016/0890-4332(95)90036-5

15. Aklilu, B. T. and Gilani, S. I., Mathematical Modeling and Simulation of a Cogeneration Plant, Applied Thermal Engineering, Vol. 30, No. 16, pp 2545-2554, 2010, http://dx.doi.org/10.1016/j.applthermaleng.2010.07.005

16. Zhang, N. and Cai, R., Analytical Solutions and Typical Characteristics of Part-load Performances of Single Shaft Gas Turbine and its Cogeneration, Energy Convers. Management, Vol. 43, No. 9-12, pp 1323-1337, 2002, http://dx.doi.org/10.1016/S0196-8904(02)00018-3 
17. Malinowski, L. and Lewandowska, M., Analytical Model-based Energy and Exergy Analysis of a Gas Micro Turbine at Part-load Operation, Applied Thermal Engineering, Vol. 57, No. 1-2, pp 125-132, 2013, http://dx.doi.org/10.1016/j.applthermaleng.2013.03.057

18. Lazaro-Alvarado, A., Gonzalez-Carmona, M. A., Dutra, J. C. C. and Coronas, A., Performance Modelling of a Micro Gas Turbine at Part-load Operation, ECOS2015 the $28^{\text {th }}$ International Conference on Efficiency, Cost, Optimization, Simulation and Environmental Impact of Energy Systems, June 30-July 3 2015, Pau- France.

19. Amaris, C., Modeling and Experimental Study of a Recovery System Exhaust Gas Microturbine, for activating a Absorption Chiller of Ammonia/Water Absorption, PFM Universitat Rovira i Virgili, Tarragona, Spain, 2009.

20. Moya, M., Microtrigeneración Advanced Systems with Gas Microturbines and Absorption Chillers for Air Dissipation, PhD Thesis, Universitat Rovira I Virgili, Tarragona, Spain, January 2011, 1-15-1-17. 